\title{
Highly sensitive persons, caregiving strategies and humour: the case of Italian and Israeli medical clowns
}

\author{
Alberto Dionigi \\ Federazione Nazionale Clowndottori \\ research@fnc-italia.org
}

\author{
Alon Goldberg \\ Education Department, Tel-Hai College \\ galgal.ezer@gmail.com
}

\begin{abstract}
The medical clown is a healthcare practitioner whose character is strictly associated with the performer's own personality. In this study, the relationships between the level of sensory processing sensitivity (SPS), caregiving strategies and humour in Italian and Israeli clowns were examined. Participants were 159 medical clowns (97 Italian and 62 Israeli), ranging from 22 to 74 years of age, who completed a demographic questionnaire, the self-reported Highly Sensitive Person Scale, the Caregiving System Scale and the BenCor. Results showed that a higher SPS was related to higher hyperactivation and deactivation, and that hyperactivation was related to lower benevolent humour and greater corrective humour. Hyperactivation negatively predicts benevolent humour but positively predicts corrective humour, beyond the effect of SPS. Deactivation had no relationship to either benevolent or corrective humour. The results are also discussed in reference to the two culture groups and to previous studies conducted with general populations.
\end{abstract}

Keywords: humour, medical clowns, sensitivity, caregiving strategies, personality

\section{Introduction}

In recent years, researchers have gained interest in the effectiveness of clowning in healthcare settings. Clowns in healthcare settings are organized into clown care units, made up of artists working alone or in pairs, and colloquially called various names: the most frequent are "clown doctors" and "medical clowns" (Dionigi, 2017). Clown doctors work in a large variety of 
medical settings, and their activity is directed to children, adults and elderly people, as well as to patients' relatives and healthcare staff (Scheyer et al., 2008).

Although many studies have proved the effectiveness of clowning as a complementary and alternative approach in decreasing negative emotions and improving positive ones in hospitalized patients and their relatives (Auerbach et al., 2013; Ford et al., 2014; Golan et al., 2009; Vagnoli et al., 2005), little is known about the personality traits of these practitioners (Dionigi 2018). Some studies have investigated the personality of comedians (Greengross \& Miller 2009), but only a few have explored the social and professional identity of clown doctors, and these were mainly conducted in specific countries, such as Italy (for a review, see Dionigi \& Canestrari, 2016). There is evidence that people who decide to clown in healthcare settings are less neurotic than the general population. Moreover, clowns are also more extroverted, open to experience, agreeable and conscientious than the general populace (Dionigi, 2016). Another Italian study focusing on the factors influencing volunteer clowns to undertake this activity (Strollo et al., 2015) has showed how people involved in healthcare clowning possess high levels of self-efficacy, and that their motivation is primarily related to the upgrading of their skills. Unfortunately, no comparisons have been made between volunteer and professional clowns. However, specific differences in personality traits were found in another study using the five-factor model (FFM) of personality (McCrae \& Costa, 2003): volunteer clowns scored higher than professionals only for Agreeableness, and no other differences were found in Neuroticism, Extroversion, Openness to experience or Conscientiousness (Dionigi, 2016).

\section{Research hypotheses}

The current study will look at specific personality traits that have been postulated as important for clown doctors (Dionigi et al., 2012). Due to the lack of studies in this field, we were interested in understanding whether clown doctors possess specific personality traits related to fundamental aspects of such practice, such as sensory processing sensitivity (SPS), caregiving strategies and virtue-related humour. Moreover, focusing in cultural differences can help to answer the question of whether benevolent and corrective humour can be found and distinguished across several countries, further supporting the relevance of the virtue gap in humour (Heintz et al., 2018).

Sensory processing sensitivity is an adult temperament trait characterized by high sensitivity of the central nervous system and a deeper cognitive processing of physical, social and emotional stimuli (Aron \& Aron, 1997; Aron et al., 2012). Specifically, sensory processing is related to how a person detects, regulates, interprets and responds to sensory stimuli (Aron \& Aron, 1997; Dunn, 2001). Each person has a different threshold for perceiving, responding to and becoming overwhelmed by sensations, which leads to different physiological and behavioural outcomes (Dunn, 2001). SPS is a genetically determined trait: individuals with high SPS are involved in a deeper cognitive processing of stimuli that is driven by higher emotional reactivity, both positive and negative, and they present specific behaviours such as greater sensitivity to subtle stimuli and the tendency to "pause to check" in novel situations. Furthermore, individuals with SPS have greater emotional responsiveness, heightened aesthetic sense, a subtle sense of humour, and creativity (Aron \& Aron, 1997). Although most sensitive people are introverted, they may enjoy interacting with others and are motivated by novelty, the seeking of new experiences, and a susceptibility to boredom (Aron, 2013; Aron \& Aron, 1997; Aron et al., 2012; Cooper, 2016). It is estimated that about 25 per cent of the population is highly sensitive (Aron \& Aron, 1997; Lionetti et al., 2018). 
With reference to personality traits, SPS has been found to be moderately related to neuroticism and emotionality (Aron \& Aron, 1997), indicating that having a sensitive sensory processing style is related, but not identical, to these constructs. When facing negative stressful experiences, individuals with high SPS become overwhelmed and display poor outcomes. These same individuals are more likely to flourish under positive and enriching experiences (Lionetti et al., 2018). Given that many SPS individuals experience sensory bombardment (Aron \& Aron, 1997), they are more susceptible to environmental influences, such as different cultural and social contexts. Hence, SPS individuals are more affected than others by negative environmental exposures (Hartman \& Belsky, 2016), experiencing higher levels of stress (Aron et al., 2005; Liss et al., 2005). This can strongly affect the sensitivity genotype by increasing its phenotype expression (Pluess, 2015), activating the sympathetic nervous system (Shoenfeld et al., 2008), and eventually magnifying their sensitivity expression.

Medical clowns were found to display higher levels of agreeableness, sensitivity to and understanding of others' needs, and compassion (Dionigi, 2016; Warren \& Spitzer, 2013). Similarly, highly sensitive individuals are characterized by emotional responsiveness, a rich inner world, awareness, and empathy (Acevedo et al., 2014; Aron \& Aron, 1997). Therefore, it can be expected that medical clowns show higher SPS than the general population.

\section{RH1: The percentage of SPS is higher in the clown sample, compared to general population.}

Caregiving strategies. According to Bowlby's attachment theory (1969, 1973, 1980), individuals' caregiving behaviours or reactions to others' distress are organized by an innate behavioural system, the caregiving behavioural system. Moreover, supportive interpersonal relationships play a central role in adaptive human development (Ainsworth et al., 1978; Bowlby, 1982). The main goal of the caregiving behavioural system is to relieve others' distress and to promote their health and welfare; individuals vary in the degree to which they are avoidant or anxious in their relationships with others (Brennan et al., 1998). Dysfunctions in the primary strategy of the caregiving system can trigger one of two secondary caregiving strategies: hyperactivation or deactivation of the caregiving system (Shaver et al., 2010).

Hyperactivation caregiving strategies are characterized as intrusive, poorly timed, and effortful. The main aim of hyperactivation is to intensify the caregiving system's primary strategy and to keep the behavioural system chronically activated until its goal is achieved. Furthermore, individuals who use hyperactivation strategies are characterized by a hypervigilant, anxious attentional focus on attachment figures and relationships, hyperactivation of negative emotions and thoughts, and failure to disconnect from psychological pain (Mikulincer \& Shaver, 2007; Shaver et al., 2010). Hyperactivation was found to be significantly associated with lower perceived self-efficacy as a caregiver, with personal distress when others need assistance, and with an attitude towards others that involves a compulsion to help, or high interdependence (Shaver et al., 2010). Strategies associated with caregiving-system deactivation, on the other hand, are actions characterized by a denial of attachment need and involve withdrawal from caregiving, low empathy and maintaining emotional distance when others seek care, closeness and comforting (Mikulincer \& Shaver, 2012, 2016). Medical clowning represents a challenging practice because of the psychological conditions the clowns face during their activity. While medical clowns should react properly under those conditions and use effective caregiving strategies (i.e. low hyperactivation and low deactivation), medical clowns who are higher in SPS, in their efforts to manage their own stress and worries while easing a patient's distress, may have more difficulty staying in character and experience more stress during their work (Dionigi et al., 2014) and activate less effective caregiving strategies. 


\section{RH2: Medical clowns high in SPS adopt both hyperactivation and deactivation strategies.}

Humour. The clown is, by definition, a curious figure that projects himself on a different wavelength than that of society's status quo (Dionigi et al., 2014). Due to its funny framework, the clown working in healthcare settings is a performer who acts foolishly and childishly to elicit positive emotions: specifically, a rise in exhilaration accompanied by smiling and laughter (Auerbach et al., 2013). Clown interventions in healthcare settings are a particular way of using humour to promote people's well-being (Dionigi et al., 2012). A sense of humour is one essential characteristic of a resilient person, rooted in the vision of humour as a tool for facing adversity (Freud, 1960). Clowning in healthcare settings does not consist of humour alone (Peacock, 2009), but humour is frequently indicated as the main component of this activity (Dionigi et al., 2012). However, research has yet to focus on this basic element for clown doctors specifically.

Humour is an umbrella term with a generally positive, socially desirable connotation (Martin, 2007). A recent approach highlights eight different comic styles derived from an interdisciplinary approach (Ruch et al., 2018), namely fun, (benevolent) humour, nonsense, wit, irony, satire/corrective humour, sarcasm, and cynicism. Furthermore, the theoretical framework of positive psychology gave rise to the idea of conceptualizing humour from a "good character" perspective (Peterson \& Seligman, 2004), exploring two forms of virtuerelated humour: the benevolent and the corrective (Ruch \& Heintz, 2016a). This view sees humour not only as a personality trait, or as a way of coping, but also as a morally guided behaviour (Ruch \& Heintz, 2016a), similar to the attitude towards humour required of the people who work as clown doctors (Koller \& Gryski, 2008). Benevolent humour adopts an accepting attitude towards the world and towards human weaknesses, and it treats them benevolently. Corrective humour, on the other hand, criticizes the wrongdoings of both individuals and institutions, and it mocks them to improve them. A recent study conducted across 25 samples from 22 countries revealed that benevolent humour was more strongly endorsed than corrective humour (Heintz et al., 2018).

Clown doctors act clumsily and in a playful way, always sharing the clown's unique, paradoxical, and humorous point of view. The character of the clown is unique, because clowning is more than just playing a clumsy role; it is an attitude towards humour (Dionigi, 2016). Unlike an actor, a clown does not play a role, but develops its character on the performer's physical and psychological characteristics (Peacock, 2009). For this reason, we decided to study humour as a morally guided behaviour instead of the use of specific styles. There are two major characters of clowns: the "white clown", who represents the rational voice of reason and who has his "clownishness" revealed either by his own ineptness or by that of his underling. The other major character is the "August", the least intelligent and most emotional character, who is also the problem maker (Dionigi et al., 2012). Clowns are comic performers who employ slapstick, physical comedy and verbal humour, and their character is strictly linked to their persona: we would expect both Italian and Israeli clown doctors to possess high benevolent and corrective humour.

Similar to attachment working models, humour styles also involve benevolent and negative views of self and others. Higher anxiety was found to predict more negative and less positive self-directed humour, while higher avoidance scores predicted less benevolent and more maladaptive other-directed humour (Cann et al., 2008). Highly dependent individuals showed an inability to use humour, sustaining the hyperactivation of the attachment system (Prunas et al., 2019). Further, anxious individuals are more susceptible to poor performance (Eysenck \& Derakshan, 2011), and anxiety has been found to be detrimental for clown doctors (Dionigi et al., 2014). 
For this reason, we further hypothesize that for medical clowns who are higher in SPS, their efforts to manage their own stress and worries while easing a patient's distress may decrease their ability to respond in a consistent manner that suits the patient's needs and that they will, therefore, report higher hyperactivation and deactivation caregiving strategies and will differ in their humour from non-SPS clowns.

RH3: The use of hyperactivation and deactivation caregiving strategies in sensitive medical clowns negatively influences the use of benevolent humour and positively influences the use of corrective humour.

Although some research has identified specific personality characteristics of clown doctors, no study has investigated whether these practitioners possess common traits, independent of the sociodemographic aspects. The main aim of this investigation was to compare the relationships between level of SPS, caregiving strategies and benevolent and corrective humour in Italian and Israeli clowns.

\section{Methods}

\subsection{Participants}

Participants were 159 clown doctors: 97 (61.0\%) Italians and $62(39.0 \%)$ Israelis. They were 96 females (60.4\%; 66 Italians and 30 Israelis) and 63 males $(39.6 \% ; 31$ Italians and 32 Israelis). The percentage of females in the Italian sample $(68.0 \%)$ was higher than in the Israeli sample (48.4\%; $Z=2.47, p=.013)$. Participants were 22 to 74 years old, with an average age of 41.26 years ( $S D=10.30$ years). They had been working as clown doctors for up to 23 years, with an average of 7.85 years $(S D=4.83)$, with no significant group differences.

\subsection{Instruments}

The demographic questionnaire developed for this study gathered information about participants' age, gender, level of education and employment status.

The Highly Sensitive Person Scale (HSPS; Aron \& Aron, 1997) measures SPS traits. The HSPS consists of 27 items related to sensitivity, rated on a 7-point scale $(1=$ not at all; 7 = extremely). Example items are, "Are you easily overwhelmed by strong sensory input?" and, "Do you have a rich, complex inner life?" In the present study, the Cronbach's alpha was .83. The total score was composed of the mean of the items, with higher scores representing greater sensitivity levels.

The Caregiving System Scale (CSS; Shaver et al., 2010) measures caregiving strategies. The questionnaire has 20 items rated on a 7-point Likert scale ranging from 1 (not at all) to 6 (very much). The CSS comprises two subscales, with 10 items each, that assess the hyperactivating (e.g., "I sometimes try to help others more than they actually want me to") and deactivating (e.g., "I don't often feel an urge to help others") strategies of caregiving. Each subscale score is obtained by calculating the mean of the items, with higher scores indicating higher levels of hyperactivating or deactivating strategies. Internal consistency for hyperactivation was $\alpha=.81$, and for deactivation was $\alpha=.81$.

The BenCor (Ruch \& Heintz, 2016a) assesses benevolent and corrective humour with six marker items each. Benevolent humour describes a humorous outlook on life that entails realistic observations and understanding of human weaknesses, but also their benevolent humorous treatment. Corrective humour involves moral-based ridicule, that is, the use of mockery to fight evil and mediocrity. The BenCor employs a 7-point Likert scale ranging from 
1 (strongly disagree) to 7 (strongly agree). Internal consistency for benevolent humour was .66 , and for corrective humour was .84. Each subscale score is obtained by calculating the sum of the items, with higher scores representing greater use of each aspect of humour.

\subsection{Procedure}

The study was conducted among a broad sample of Italian and Israeli medical clowns. E-mails were sent to the coordinators of several clown care units, asking them to forward the message to the certified clowns belonging to each clown care unit. The e-mail contained a link to the survey created on Survey Monkey, as well as a short statement describing the purpose of the survey. To keep the surveys anonymous, no identifiable information (e.g. name, ID number, or e-mail address) was collected.

\subsection{Data analysis}

Means, standard deviations and intercorrelations between the study variables were first calculated. Gender differences were assessed with $t$-tests, and correlations with age and seniority in medical clowning were calculated. A multivariate analysis of covariance (MANCOVA) was used to assess nationality differences in the study variables, controlling for gender and seniority in medical clowning. Multiple hierarchical regressions were used to predict hyperactivation and deactivation with SPS, benevolent and corrective humour with SPS, hyperactivation and deactivation. Nationality, gender and seniority in medical clowning were entered at step 1 as control variables. The mediating role of hyperactivation in the relationship between SPS and benevolent and corrective humour was examined with the PROCESS procedure (Hayes, 2013), with bootstrapping and 10,000 samples, using 95\% confidence intervals (95\% CIs).

\section{Results}

Distribution of the study variables revealed that mean SPS was at about the scale mid-point (Table 1). Mean hyperactivation was somewhat below the scale mid-point, and mean deactivation was significantly lower than mean hyperactivation $[t(158)=11.12, p<.001]$. Mean benevolent humour was rather high, and mean corrective humour was at about the scale mid-point, being significantly lower than mean benevolent humour $[t(158)=14.95, p<.001]$. Hyperactivation and deactivation were positively interrelated, and benevolent and corrective humour were positively interrelated as well.

Correlations revealed that SPS was positively related to both hyperactivation and deactivation. Hyperactivation was negatively related to benevolent humour but positively related to corrective humour. Other correlations were non-significant.

An examination of the relationships between the study variables and background characteristics revealed several interesting findings. Both benevolent and corrective humour were higher among males $(M=5.88, S D=0.75$ and $M=4.45, S D=1.35$, respectively $)$ than among females $(M=5.53, S D=0.76$ and $M=3.78, S D=1.29$, respectively) $[t(157)=2.77$, $p<.01$ and $t(157)=3.06, p<.01$, respectively]. No gender differences were found for SPS, hyperactivation or deactivation. Age and seniority in medical clowning were negatively related to hyperactivation $(r=-.21, p=.007$, and $r=-.30, p<.001)$. Other correlations with age and seniority in medical clowning were non-significant. Age and seniority in medical clowning were positively interrelated $(r=.38, p<.001)$. 
Table 1: Means, standard deviations and correlations for the study variables $(N=159)$

\begin{tabular}{|c|c|c|c|c|c|}
\hline Variable & $\begin{array}{c}M \\
(S D)\end{array}$ & 2. & 3. & 4. & 5. \\
\hline 1. SPS & $\begin{array}{l}3.95 \\
(0.86)\end{array}$ & $.39 * * *$ & $.27 * * *$ & -.09 & .01 \\
\hline 2. Hyperactivation & $\begin{array}{c}2.66 \\
(0.99)\end{array}$ & & $.29 * * *$ & $-.26^{* *}$ & $.17^{*}$ \\
\hline 3. Deactivation & $\begin{array}{l}1.73 \\
(0.74)\end{array}$ & & & -.13 & -.07 \\
\hline $\begin{array}{l}\text { 4. Benevolent } \\
\text { humour }\end{array}$ & $\begin{array}{c}5.66 \\
(0.77)\end{array}$ & & & & $.29 * * *$ \\
\hline $\begin{array}{l}\text { 5. Corrective } \\
\text { humour }\end{array}$ & $\begin{array}{c}4.03 \\
(1.35)\end{array}$ & & & & \\
\hline
\end{tabular}

$* p<.05, * * p<.01, * * * p<.001$

Differences in the study variables by nationality were assessed with a MANCOVA, controlling for gender $(1=$ male, $0=$ female) and seniority in medical clowning (Table 2$)$. Results reveal significant differences for SPS and deactivation; both were higher among Israeli than among Italian medical clowns. No other differences were found.

Twelve participants in the Italian sample $(12.4 \%)$ were classified as being highly sensitive, compared with 27 participants $(43.5 \%)$ in the Israeli sample, a significant difference $(Z=4.46$, $p<.001)$.

Table 2: Means, standard deviations and $F$ values for the study variables by group $(N=159)$

\begin{tabular}{lccc}
\hline & Italian & Israeli & \\
Variable & $M$ & $M$ & $F(1,155)$ \\
\hline SPS & $(S D)$ & $(S D)$ & $\left(\eta^{2}\right)$ \\
Hyperactivation & 3.65 & 4.47 & $46.84^{* * *}$ \\
& $(0.74)$ & $(0.81)$ & $(.24)$ \\
Deactivation & 2.58 & 2.76 & 1.94 \\
Benevolent humour & $(0.99)$ & $(1.03)$ & $(.01)$ \\
& 1.58 & 1.98 & $9.52^{* *}$ \\
Corrective humour & $(0.58)$ & $(0.93)$ & $(.06)$ \\
& 5.66 & 5.67 & 0.11 \\
& $(0.82)$ & $(0.70)$ & $(.00)$ \\
& 4.10 & 3.94 & 1.43 \\
\hline
\end{tabular}

$* p<.05, * * p<.01, * * * p<.001$

Table 3 shows the results of multiple hierarchical regressions, predicting hyperactivation and deactivation with SPS, and humour practices with SPS, hyperactivation and deactivation. Nationality $(1=$ Israel, $0=$ Italian $)$, gender $(1=$ male, $0=$ female $)$ and seniority in medical clowning were entered at step 1 as control variables. Results reveal that the four regression models are significant, although the total explained variance is low.

SPS positively predicts both hyperactivation and deactivation, beyond nationality, gender and seniority in medical clowning. Hyperactivation negatively predicts benevolent humour but positively predicts corrective humour, beyond the effect of SPS. Deactivation had no 
relationship with either benevolent or corrective humour. That is, higher SPS was related to higher hyperactivation and deactivation, and hyperactivation was related to lower benevolent humour and greater corrective humour.

Thus, as SPS is related to hyperactivation, and as hyperactivation is related to both benevolent and corrective humour, hyperactivation may be a mediator between SPS and benevolent and corrective humour. Mediation was examined with the PROCESS procedure (Hayes, 2013), controlling for nationality $(1=$ Israel, $0=$ Italian $)$, gender $(1=$ male, $0=$ female) and seniority in medical clowning. Both mediated relationships were found to be significant: for benevolent humour, the coefficient $=-0.074, S E=0.034,95 \% C I=-0.15$, -0.02 ; and for corrective humour, the coefficient $=0.140, S E=0.066,95 \% C I=0.02,0.28$. That is, higher SPS is related to higher hyperactivation, which is thereby related to a lower use of benevolent humour and a greater use of corrective humour. 
Table 3: Multiple hierarchical regressions predicting hyperactivation, deactivation and benevolent and corrective humour $(N=159)$

\begin{tabular}{|c|c|c|c|c|c|c|c|c|c|c|c|c|}
\hline & \multicolumn{3}{|c|}{ Hyperactivation } & \multicolumn{3}{|c|}{ Deactivation } & \multicolumn{3}{|c|}{ Benevolent humour } & \multicolumn{3}{|c|}{ Corrective humour } \\
\hline & $B$ & $S E$ & $\beta$ & $B$ & $S E$ & $\beta$ & $B$ & $S E$ & $\beta$ & $B$ & $S E$ & $\beta$ \\
\hline \multicolumn{13}{|l|}{ Step 1} \\
\hline Nationality & 0.25 & 0.16 & .12 & 0.36 & 0.12 & $.24 * *$ & -0.04 & 0.13 & -.03 & -0.26 & 0.22 & -.09 \\
\hline Gender & -0.18 & 0.16 & -.09 & 0.10 & 0.12 & .06 & 0.30 & 0.13 & $.19^{*}$ & 0.76 & 0.22 & $.27 * * *$ \\
\hline Seniority & -0.06 & 0.02 & $-.28 * * *$ & -0.01 & 0.01 & -.05 & 0.01 & 0.01 & .07 & -0.03 & 0.02 & -.11 \\
\hline Adj. $R^{2}$ & $.09 * * *$ & & & $.05^{*}$ & & & .03 & & & & & $.06 * *$ \\
\hline \multicolumn{13}{|l|}{ Step 2} \\
\hline Nationality & -0.11 & 0.17 & -.06 & 0.22 & 0.13 & .14 & 0.03 & 0.15 & .02 & -0.33 & 0.25 & -.12 \\
\hline Gender & -0.10 & 0.15 & -.05 & 0.13 & 0.12 & .09 & 0.28 & 0.13 & $.18^{*}$ & 0.77 & 0.23 & $.28 * * *$ \\
\hline Seniority & -0.04 & 0.01 & $-.21 * *$ & -0.01 & 0.01 & -.02 & 0.01 & 0.01 & .05 & -0.03 & 0.02 & -.10 \\
\hline SPS & 0.43 & 0.10 & $.37 * * *$ & 0.17 & 0.08 & $.20 *$ & -0.09 & 0.08 & -.10 & 0.08 & 0.14 & .05 \\
\hline $\operatorname{Adj} . R^{2}$ & & & & & & & .03 & & & & & $.06^{*}$ \\
\hline \multicolumn{13}{|l|}{ Step 3} \\
\hline Nationality & & & & & & & 0.04 & 0.14 & .02 & -0.21 & 0.25 & -.08 \\
\hline Gender & & & & & & & 0.27 & 0.13 & $.17 *$ & 0.86 & 0.22 & $.31 * * *$ \\
\hline Seniority & & & & & & & 0.01 & 0.01 & .01 & -0.02 & 0.02 & -.05 \\
\hline SPS & & & & & & & -0.01 & 0.09 & -.01 & -0.04 & 0.15 & -.02 \\
\hline Hyperactivation & & & & & & & -0.15 & 0.07 & $-.20 *$ & 0.36 & 0.13 & $.26 * *$ \\
\hline Deactivation & & & & & & & -0.11 & 0.09 & -.11 & -0.27 & 0.15 & -.15 \\
\hline Adj. $R^{2}$ & & $.19 * * *$ & & & $.08 * *$ & & & $.07 *$ & & & $.10 * *$ & \\
\hline$F$ & \multicolumn{3}{|c|}{$F(4,154)=10.17 * * *$} & \multicolumn{3}{|c|}{$F(4,154)=4.19 * *$} & \multicolumn{3}{|c|}{$F(6,152)=2.81 *$} & \multicolumn{3}{|c|}{$F(6,152)=3.80^{* *}$} \\
\hline
\end{tabular}

$* p<.05, * * p<.01, * * * p<.001$ 


\section{Discussion}

Within the past two decades, there has been a surge of interest in investigating the effects of clown intervention in a large variety of clinical settings (Dionigi, 2018; Ford et al., 2014). However, only a few studies have investigated the personality traits of medical clowns, and they have been in specific countries (Dionigi, 2017; Dionigi \& Canestrari, 2016). The main aim of this study was to investigate the relationship between levels of SPS, caregiving strategies and benevolent and corrective humour in two different groups: Italian and Israeli medical clowns.

Both benevolent and corrective humour were found to be higher for males than for females: a recent study of the general population found that although males and females did not substantially differ in their levels of benevolent humour, males scored higher than females in corrective humour (Heintz et al., 2018). However, the result of our research is not surprising, as several studies have shown that men are generally funnier than women (Kotthoff, 2006; Lewis, 2000; Mickes et al., 2012), especially for critical or affective forms of humour (Lampert \& Ervin-Tripp, 2006; Martin et al., 2003), and have been found to possess higher humour ability (Greengross \& Miller, 2011).

The mean SPS of the total sample was at about the scale mid-point. However, when comparing the two groups, more Israeli clowns were classified as being highly sensitive and using deactivation than Italian clowns. Usually, about 25 per cent of the general population are hypothesized to be highly sensitive (Aron \& Aron, 1997; Lionetti et al., 2018). As the medical clown is a comic and creative character, higher in agreeableness than the general population (Dionigi, 2016), we would expect to find a significantly larger number of highly sensitive medical clowns. However, the percentage of those with SPS was somewhat below the general population for the Italian sample and higher than the general population for the Israeli sample. One possible explanation for this difference is cultural influence: a culture can be conceptualized as a source of meaningful concepts with which people interpret and understand their environment and themselves (Kashima, 2001), and can influence the cognitive processing of physical, social and emotional stimuli (Vogeley \& Roepstorff, 2009). Furthermore, when cultural conceptions may be appropriated to form their own self-concepts, that may affect the variability of the phenomenal self (Kashima et al., 2004).

SPS is an adult temperament trait characterized by high sensitivity of the central nervous system and a deeper cognitive processing of the self and environmental stimuli (Aron \& Aron, 1997; Aron et al., 2012). Specifically, sensory processing is related to how a person detects, regulates, interprets and responds to sensory stimuli (Aron \& Aron, 1997; Dunn, 2001). Nevertheless, exposure to specific environmental stimuli can lead individuals to experience higher levels of sensory bombardment, increasing their level of sensitivity (Aron \& Aron, 1997). Hence, negative experiences and environmental exposures to high levels of stress (Aron et al., 2005; Hartman \& Belsky, 2016; Liss et al., 2005) might increase the phenotype expression of the sensitivity genotype (Pluess, 2015), and activate the sympathetic nervous system (Shoenfeld et al., 2008). Therefore, although about 1.4 billion people worldwide are highly sensitive, some countries or cultures are better suited for highly sensitive persons than others (Aron, 2013).

Both Italian and Israeli clowns reported relatively low deactivation compared with hyperactivation, as expected in an effective caregiver (Shaver et al., 2010). Yet, when considering correlations with SPS, highly sensitive medical clowns showed positive correlations with both hyperactivation and deactivation. Both hyperactivating and deactivating strategies represent negative mental representations of caregiving and maladaptive secondary emotion regulation strategies (Mikulincer et al., 2003; Shaver et al., 2010) that have been found 
to be associated with psychopathology (Brenning et al., 2012). Medical clowns are humour practitioners working in stressful environments (e.g., the medical setting). They are required to regulate their emotions and to possess social skills and prosocial motivation, which have been found to be protective factors (Shaver et al., 2010). SPS clowns can be more prone to experience stress and symptoms of illness (Benham, 2006), intensify their emotional responsiveness (Aron \& Aron 1997), and cope with inefficient caregiving strategies when facing touching situations (e.g., patients in need). A further explanation could be that medical clowns, who are people high in Conscientiousness (Dionigi, 2016), through "hyperactivating" strategies, such as being hypervigilant to social and emotional signals from others (Chris Fraley et al., 2006), keep their caregiving chronically activated (Shaver et al., 2010) in order to be more motivated in their practice.

Interestingly, hyperactivation was negatively related to benevolent humour but positively related to corrective humour. Earlier studies demonstrated that attachment-insecure behaviours, which demonstrate ineffective caregiving strategies, are positively related to maladaptive humour styles (Cann et al., 2008; Kazarian \& Martin, 2004; Martin, 2007; Miczo et al., 2009; Saroglou \& Scariot, 2002; Taher et al., 2008). Corrective humour refers to moralbased ridicule, such as the use of mockery (Ruch \& Heintz, 2016a), and aggressive humour has its counterparts both in the styles of everyday humorous conduct (earthy and mean-spirited) and in the comic styles (wit, satire, sarcasm and cynicism) (Ruch \& Heintz, 2016b). Although both benevolent and corrective humour were conceptualized from a "good character" perspective (Peterson \& Seligman, 2004), corrective humour seems to be closer to aggressive humour, explaining the positive correlation with the hyperactivation caregiving strategies.

It is worth mentioning that deactivation was not associated with either benevolent or corrective humour. We suggest that although avoidance predicted less benevolent and more maladaptive other-directed humour in earlier research (Cann et al., 2008), the extremely low levels of deactivation strategies that were found in the current study is a possible cause of this result.

Finally, the role of hyperactivation as a mediator between SPS and both benevolent and corrective humour strategies suggests that highly sensitive clowns keep their caregiving chronically activated until their goal is achieved (Shaver et al., 2010). Thus, their coping strategies are associated with hypervigilance and an exaggerated appraisal of their patient's needs, which might be expressed as inconsistent, intrusive care that is often asynchronous with the patient's needs (Mikulincer \& Shaver, 2016) and which may bring about a higher use of aggressive humour (i.e., corrective humour) and less use of benevolent humour.

These results highlight the importance of evaluating the personality of people who approach the work of a clown doctor, and provide useful information to ensure that the most appropriate candidate is hired. Moreover, in the context of the challenging profession and setting they engage in, highly sensitive clowns are characterized by ineffective caregiving strategies and a more aggressive humour practice. Therefore, targeting highly sensitive medical clowns, both before their initial training and during their ongoing activity, can help them during this challenging practice. Providing them emotional and professional support focused on regulating their emotions could facilitate their use of more effective caregiving strategies, improve clown-patient interaction, and produce better outcomes for their patients.

Some limitations need to be acknowledged for consideration by future researchers. First, no instruments were used to assess the level of stress that medical clowns experience. Second, it would be of interest to replicate the study in different countries, to compare these results. Finally, as personality is a complex phenomenon, future studies are encouraged to explore the differential influence of SPS on personality traits that can play a role in medical clowning, such as narcissism and coping strategies. 


\section{Acknowledgements}

This work was supported by the Dream Doctors Association and by the Italian Federazione Nazionale Clowndottori. We owe special gratitude to all the medical clowns who participated in the research.

\section{References}

Acevedo, B. P., Aron, E. N., Aron, A., Sangster, M.-D., Collins, N. \& Brown, L. L. (2014). 'The highly sensitive brain: An fMRI study of sensory processing sensitivity and response to others' emotions'. Brain and Behavior 4, pp. 580-594.

Ainsworth, M. S., Blehar, M. C., Waters, E. \& Wall, S. (1978). Patterns of Attachment: A Psychological Study of the Strange Situation. Oxford, England: Lawrence Erlbaum.

Aron, E. \& Aron, A. (1997). 'Sensory-processing sensitivity and its relation to introversion and emotionality'. Journal of Personality and Social Psychology 73 (2), pp. 345-368. https://doi.org/10.1037/0022-3514.73.2.345

Aron, E. N., Aron, A. F. \& Davies, K. M. (2005). 'Adult shyness: The interaction of temperamental sensitivity and an adverse childhood environment'. Personality and Social Psychology Bulletin 31 (2), pp. 181-197.

Aron, E. N., Aron, A. \& Jagiellowicz, J. (2012). 'Sensory processing sensitivity: A review in the light of the evolution of biological responsivity'. Personality and Social Psychology Review 16 (3), pp. 262-282. https://doi.org/10.1177/1088868311434213

Aron, E. N. (2013). The Highly Sensitive Person: How to Thrive When the World Overwhelms You. New York: Kensington.

Auerbach, S., Hofmann, J., Platt, T. \& Ruch, W. (2013). 'An investigation of the emotions elicited by hospital clowns in comparison to circus clowns and nursing staff'. European Journal of Humour Research 1 (3), pp. 26-54. https://doi.org/10.7592/EJHR2013.1.3.auerbach

Benham, G. (2006). 'The highly sensitive person: Stress and physical symptom reports'. Personality and Individual Differences 40 (7), 1433-1440. https://doi.org/10.1016/j.paid.2005.11.021

Bowlby, J. (1969). Attachment and Loss: Vol. 1. Attachment. Reading, MA: Addison-Wesley.

Bowlby, J. (1973). Attachment and Loss: Vol. 2. Separation: Anxiety and Anger. New York: Basic Books.

Bowlby, J. (1980). Attachment and Loss: Vol. 3. Loss: Sadness and Depression. New York: Basic Books.

Bowlby, J. (1982). 'Attachment and loss: Retrospect and prospect'. American Journal of Orthopsychiatry 52 (4), pp. 664-678. https://doi.org/10.1111/j.19390025.1982.tb01456.x

Brennan, K. A., Clark, C. L. \& Shaver, P. R. (1998). 'Self-report measurement of adult attachment: An integrative overview', in Simpson, J. A. \& Rholes, W. S. (eds.), Attachment Theory and Close Relationships, New York: Guilford, pp. 46-76.

Brenning, K. M., Soenens, B., Braet, C. \& Bosmans, G. (2012). 'Attachment and depressive symptoms in middle childhood and early adolescence: Testing the validity of the emotion regulation model of attachment'. Personal Relationships 19 (3), pp. 445-464.

Cann, A., Norman, M. A., Welbourne, J. L. \& Calhoun, L. G. (2008). 'Attachment styles, conflict styles and humour styles: Interrelationships and associations with relationship satisfaction'. European Journal of Personality: Published for the European Association of Personality Psychology 22 (2), pp. 131-146. 
Chris Fraley, R., Niedenthal, P. M., Marks, M., Brumbaugh, C. \& Vicary, A. (2006). 'Adult attachment and the perception of emotional expressions: Probing the hyperactivating strategies underlying anxious attachment'. Journal of Personality 74 (4), pp. 1163-1190.

Cooper, T. M. (2016). Thrill: The High Sensation Seeking Highly Sensitive Person. Ozark, MO: Invictus.

Dionigi, A. (2018). 'Healthcare clowning: Use of specific complementary and alternative medicine for hospitalized children'. OBM Integrative and Complementary Medicine 3, 2. https://doi.org/10.21926/obm.icm.1802009

Dionigi, A. (2017). 'Clowning as a complementary approach for reducing iatrogenic effects in pediatrics'. AMA Journal of Ethics 19 (8), pp. 775-782. https://doi.org/10.1001/journalofethics.2017.19.8.stas1-1708.

Dionigi, A. (2016). 'Personality of clown doctors: An exploratory study'. Journal of Individual Differences 37 (1), pp. 49-55. https://doi.org/10.1027/1614-0001/a000187

Dionigi, A. \& Canestrari, C. (2016). 'Clowning in health care settings: The point of view of adults'. Europe's Journal of Psychology 12 (3), pp. 473-488. https://doi.org/10.5964/ejop.v12i3.1107.

Dionigi, A., Flangini, R. \& Gremigni, P. (2012). 'Clowns in hospitals', in Gremigni, P. (ed.), Humor and Health Promotion, New York: Nova Science, pp. 213-227.

Dionigi, A., Ruch, W. F. \& Platt, T. (2014). 'Components and determinants of the shift between own persona and the clown persona: A hierarchical analysis'. The European Journal of Humour Research 1 (4), pp. 58-80.

Dunn, W. (2001). 'The sensations of everyday life: Empirical, theoretical, and pragmatic considerations'. The American Journal of Occupational Therapy 55 (6), pp. 608-620. https://doi.org/10.5014/ajot.55.6.608

Eysenck, M. W. \& Derakshan, N. (2011). 'New perspectives in attentional control theory'. Personality and Individual Differences 50 (7), pp. 955-960.

Ford, K., Courtney-Pratt, H., Tesch, L. \& Johnson, C. (2014). 'More than just clownsClown doctor rounds and their impact for children, families and staff'. Journal of Child Health Care 18 (3), pp. 286-296.

Freud, S. (1960). Jokes and Their Relation to the Unconscious. New York: Norton.

Golan, G., Tighe, P., Dobija, N., Perel, A. \& Keidan, I. (2009). 'Clowns for the prevention of preoperative anxiety in children: A randomized controlled trial.' Pediatric Anesthesia 19 (3), pp. 262-266.

Greengross, G. \& Miller, G. (2011). 'Humour ability reveals intelligence, predicts mating success, and is higher in males'. Intelligence 39 (4), pp. 188-192.

Greengross, G. \& Miller, G. F. (2009). 'The Big Five personality traits of professional comedians compared to amateur comedians, comedy writers, and college students'. Personality and Individual Differences 47 (2), pp. 79-83. https://doi.org/10.1016/j.paid.2009.01.045

Hartman, S. \& Belsky, J. (2016). 'An evolutionary perspective on family studies: Differential susceptibility to environmental influences'. Family Process 55 (4), pp. 700-712. https://doi.org/10.1111/famp.12161

Hayes, A. F. (2013). Introduction to Mediation, Moderation, and Conditional Process Analysis: A Regression Based Approach. New York: Guilford.

Heintz, S., Ruch, W., Platt, T., Pang, D., Carretero-Dios, H., Dionigi, A. ... \& Torres-Marin, J. (2018). 'Psychometric comparisons of benevolent and corrective humour across 22 countries: The virtue gap in humour goes international'. Frontiers in Psychology 9 (92). https://doi.org/10.3389/fpsyg.2018.00092 
Kashima, Y. (2001). 'Culture and social cognition: Toward a social psychology of cultural dynamics', in Matsumoto, D. (ed.), Handbook of Culture and Psychology, New York: Oxford University Press, pp. 325-360.

Kashima, Y., Kashima, E., Farsides, T., Kim, U., Strack, F., Werth, L. \& Yuki, M. (2004). 'Culture and context-sensitive self: The amount and meaning of context-sensitivity of phenomenal self differ across cultures'. Self and Identity 3 (2), pp. 125-141.

Kazarian, S. S. \& Martin, R. A. (2004). 'Humour styles, personality, and well-being among Lebanese university students'. European Journal of Personality 18 (3), pp. 209-219.

Koller, D. \& Gryski, C. (2008). 'The life threatened child and the life enhancing clown: Towards a model of therapeutic clowning'. Evidence-Based Complementary and Alternative Medicine 5 (1), pp. 17-25.

Kotthoff, H. (2006). 'Gender and humor: The state of the art'. Journal of Pragmatics 38 (1), pp. 4-25.

Lampert, M. D. \& Ervin-Tripp, S. M. (2006). 'Risky laughter: Teasing and self-directed joking among male and female friends'. Journal of Pragmatics 38 (1), pp. 51-72.

Lewis, M. W. (2000). 'Exploring paradox: Toward a more comprehensive guide'. Academy of Management Review 25 (4), pp. 760-776.

Lionetti, F., Aron, A., Aron, E. N., Burns, G. L., Jagiellowicz, J. \& Pluess, M. (2018). 'Dandelions, tulips and orchids: Evidence for the existence of low-sensitive, mediumsensitive and high-sensitive individuals'. Translational Psychiatry 8 (1), 24. https://doi.org/10.1038/s41398-017-0090-6

Liss, M., Timmel, L. Baxley, K. \& Killingsworth, P. (2005). 'Sensory processing sensitivity and its relation to parental bonding, anxiety, and depression'. Personality and Individual Differences 39 (8), pp. 1429-1439. https://doi.org/10.1016/j.paid.2005.05.007

Martin, R. A. (2007). The Psychology of Humour: An Integrative Approach. Burlington, MA: Elsevier Academic.

Martin, R. A., Puhlik-Doris, P., Larsen, G., Gray, J. \& Weir, K. (2003). 'Individual differences in uses of humor and their relation to psychological well-being: Development of the Humor Styles Questionnaire'. Journal of Research in Personality 37 (1), pp. 4875.

McCrae, R. R. \& Costa, P. T. Jr. (2003). Personality in Adulthood: A Five-Factor Theory Perspective. New York: Guilford.

Mickes, L., Walker, D. E., Parris, J. L., Mankoff, R. \& Christenfeld, N. J. (2012). 'Who's funny: Gender stereotypes, humour production, and memory bias'. Psychonomic Bulletin \& Review 19 (1), pp. 108-112.

Miczo, N., Averbeck, J. M. \& Mariani, T. (2009). 'Affiliative and aggressive humor, attachment dimensions, and interaction goals'. Communication Studies 60 (5), pp. 443459.

Mikulincer, M. \& Shaver, P. R. (2007). Attachment in Adulthood: Structure, Dynamics, and Change. New York: Guilford.

Mikulincer, M. \& Shaver, P. R. (2012). 'Adult attachment orientations and relationship processes'. Journal of Family Theory \& Review 4 (4), pp. 259-274. https://doi.org/10.1111/j.1756-2589.2012.00142.x

Mikulincer, M. \& Shaver, P. R. (2016). Attachment in Adulthood: Structure, Dynamics, and Change. New York: Guilford.

Mikulincer, M., Shaver, P. R. \& Pereg, D. (2003). 'Attachment theory and affect regulation: The dynamics, development, and cognitive consequences of attachment-related strategies'. Motivation and Emotion 27 (2), pp. 77-102.

Peacock, L. (2009). Serious Play. Modern Clown Performances. Bristol: Intellect Books. 
Peterson, C. \& Seligman, M. E. (2004). Character Strengths and Virtues: A Handbook and Classification (Vol. 1). Oxford: Oxford University Press.

Pluess, M. (2015). 'Individual differences in environmental sensitivity'. Child Development Perspectives 9 (3), pp. 138-143. https://doi.org/10.1111/cdep.12120

Prunas, A., Di Pierro, R., Huemer, J. \& Tagini, A. (2019). 'Defense mechanisms, remembered parental caregiving, and adult attachment style'. Psychoanalytic Psychology $36(1), 64-72$.

Ruch, W. \& Heintz, S. (2016a). 'The virtue gap in humour: Exploring benevolent and corrective humour'. Translational Issues in Psychological Science 2 (1), pp. 35-45. https://doi.org/10.1037/tps0000063

Ruch, W. \& Heintz, S. (2016b). 'The German version of the Humor Styles Questionnaire: Psychometric properties and overlap with other styles of humor'. Europe's Journal of Psychology 12 (3), pp. 434-455. https://doi.org/10.5964/ejop.v12i3.1116

Ruch, W., Heintz, S., Platt, T., Wagner, L. \& Proyer, R. T. (2018). 'Broadening humor: Comic styles differentially tap into temperament, character, and ability'. Frontiers in Psychology 9, 6. https://doi.org/10.3389/fpsyg.2018.00006

Saroglou, V. \& Scariot, C. (2002). 'Humor Styles Questionnaire: Personality and educational correlates in Belgian high school and college students'. European Journal of Personality 16 (1), pp. 43-54.

Shoenfeld, Y., Zandman-Goddard, G., Stojanovich, L., Cutolo, M., Amital, H., Levy, Y. ... Sherer, Y. (2008). 'The mosaic of autoimmunity: Hormonal and environmental factors involved in autoimmune diseases'. The Israel Medical Association Journal 10 (1), pp. 812.

Shaver, P. R., Mikulincer, M. \& Shemesh-Iron, M. (2010). 'A behavioral-systems perspective on prosocial behavior', in Mikulincer, M. \& Shaver, P. R. (eds.), Prosocial Motives, Emotions, and Behavior: The Better Angels of Our Nature, Washington, DC: American Psychological Association, pp. 73-91.

Scheyer, R., Nuttman-Shwartz, O. \& Ziyoni, H. (2008). 'The definition of the medical clown's role with adult patients'. Harefuah 147 (1), pp. 25-29.

Strollo, M. R., Romano, A. \& Rea, G. (2015). 'Social commitment of volunteering in clowntherapy: An empowering empirical research'. Ricerche di Pedagogia e Didattica. Journal of Theories and Research in Education 10 (3), pp. 45-79.

Taher, D., Kazarian, S. S. \& Martin, R. A. (2008). 'Validation of the Arabic Humor Styles Questionnaire in a community sample of Lebanese in Lebanon'. Journal of CrossCultural Psychology 39 (5), pp. 552-564.

Vagnoli, L., Caprilli, S., Robiglio, A. \& Messeri, A. (2005). 'Clown doctors as a treatment for preoperative anxiety in children: A randomized, prospective study.' Pediatrics 116 (4), pp. e563-e567.

Vogeley, K. \& Roepstorff, A. (2009). 'Contextualising culture and social cognition'. Trends in Cognitive Sciences 13 (12), pp. 511-516.

Warren, B. \& Spitzer, P. (2013). Smiles Are Everywhere: Integrating Clown-Play into Healthcare Practice. London: Routledge. 